\title{
Increasing market interconnection: An analysis of the Italian electricity spot market ${ }^{\text {放 }}$
}

\author{
Federico Boffa ${ }^{\mathrm{a}, *}$, Viswanath Pingali $^{\mathrm{b}}$, Davide Vannoni $^{\mathrm{c}}$ \\ ${ }^{a}$ Department of Legal and Economic Studies, University of Macerata, Jesi Campus, and HERMES, Torino, Italy \\ ${ }^{\mathrm{b}}$ Assistant Professor, Institute of Financial Management and Research, 24, Kothari Road, Chennai, India \\ c Department of Economics “G. Prato”, University of Torino, and Collegio Carlo Alberto, Italy
}

\section{A R T I C L E I N F O}

\section{Article history:}

Received 27 November 2007

Received in revised form 8 October 2009

Accepted 11 October 2009

Available online 17 October 2009

\section{JEL classification:}

$\mathrm{H} 44$

L21

L22

L50

L94

\section{Keywords:}

Transmission constraints

Zonal pricing

Congestion

Electricity industry

\begin{abstract}
A B S T R A C T
We estimate the benefits (in terms of savings to end-users) resulting from an improved interconnectivity in the Italian electricity spot market. The market is currently divided into two geographic zones - North and South - with limited inter-zonal transmission capacity that often induces congestion, and hence potential inefficiency. By simulating a fully interconnected market, we predict that the total spot market expenditure would reduce substantially. Moreover, since savings do not increase linearly with the size of new transmission capacity, even a slight increment to transmission capacity is found to substantially reduce endusers' expenditures. Finally, our analysis shows that the (partly State owned) dominant firm in the market is not maximizing short-term profits.
\end{abstract}

(c) 2009 Elsevier B.V. All rights reserved.

\section{Introduction}

In the Lisbon agenda, in March 2002, the European Union recognized market integration - both within, and across its member countries - as a prerequisite for sustained economic growth. In this paper we quantify the expenditure reduction that results from one such interconnection: the case of the Italian electricity spot market. Specifically, our study has two aims. The first one is to characterize the objective function of a pivotal electricity generator in a semi-regulated environment with a mixed ownership structure: the Italian treasury and private investors. The second one is to estimate the expenditure reduction in the spot market

\footnotetext{
is We are grateful to the editor Ali Hortacsu and to an anonymous referee. We are indebted to Robert Porter, John Panzar and Andrew Sweeting for several insights throughout this project. We also thank James Dana and Shane Greenstein for useful suggestions. Discussions with Carlo Andrea Bollino, Michael Coates, Reinout DeBock, Pablo Guerron, Jakub Kastl, Lynne Kiesling, Piotr Kuszewski, Dan Liu, Lyndon Moore, Arijit Mukherjee, Diego Piacentino, Salvatore Piccolo, Maria Salgado, Carlo Scarpa, and Fan Zhang are gratefully acknowledged. All errors and omissions are solely our responsibility. We thank REF for providing data. Viswanath Pingali acknowledges financial support from the Transportation Center and the Center for the Study of Industrial Organization, Northwestern University. Davide Vannoni acknowledges financial support from Regione Piemonte, Converging Technologies Research Project ICT4Law. Federico Boffa acknowledges financial support from Free University of Bolzano.

* Corresponding author.

E-mail addresses: federico.boffa@unimc.it (F. Boffa),vpingali@gmail.com (V. Pingali), vannoni@econ.unito.it (D. Vannoni).
}

after congestion removal - in the form of lower electricity prices primarily due to a more efficient utilization of existing generation capacity.

The Italian electricity market is a good example for understanding the benefits of improved market interconnection. At present, there is a hot debate in Italy regarding infrastructural enhancements, primary among which is the discussion on the electricity transmission network. While the proponents of such venture argue that an improved network would reduce prices substantially, its opponents claim that it would lead to environmental damages without bringing about any significant benefits to end-users. To our knowledge, there is no scientific attempt on either side to quantify either costs or benefits. Therefore, our study can be viewed as partially bridging this gap by estimating the benefits of interconnection in the spot market.

Moreover, the structure of the Italian electricity spot market is particularly suitable for addressing the question at hand. Currently, the market is divided into several zones, with the amount of electricity that can flow across zones being limited due to insufficient transmission capacity. Generators, with varying degrees of efficiency and capacity, are located all over the country. While a no-arbitrage condition ensures that the market clearing price is the same across all zones when the transmission capacity is not fully saturated, zonal prices differ when the transmission constraint is binding. One way to eliminate this price difference is to invest in inter-zonal transmission capacity, so that generators can reallocate production among more efficient units, thereby reducing overall costs. Therefore, the question 
addressed in our paper can be restated as follows: what is the change in the expenditure incurred by the Italian economy on the electricity spot market, after sufficient inter-zonal transmission capacity is installed such that the price difference between zones is reduced or completely eliminated? Lower electricity prices are an indication of a more efficient market. While in the short-run demand is inelastic, and thus total welfare is invariant to price changes, in the long run this does not occur, since the elasticity of demand is higher.

Expenditure reductions from interconnection are computed based on a behavioral assumption on the dominant player in the market, Enel. A natural assumption of market leader being a short-run profit maximizer need not be an appropriate one in the Italian case for a variety of reasons. First, Enel is a partly State-owned firm. Second, electricity is a necessary good, and hence the fear of regulatory intervention is strong if there is an evidence of exploitation of market power. Finally, there is a potential chance of entry if short-run profits were too high. ${ }^{1}$ In other words, dynamic considerations could lead a firm away from myopic profit maximization paradigm in the short run. Therefore we assume that Enel's objective function has two portions. The first one is the short-run profit maximization and the second one is the minimization of consumers' expenditure. While the former represents the short-run interest of Enel's private investors, the latter is a proxy both for Enel's long run profit considerations (prevention of regulatory retaliation and entry), as well as the public ownership incentives (end-users' welfare).

We identify the relative weights of these two contrasting objectives empirically. We find that Enel places a weight of roughly $2 / 3$ on its profits and $1 / 3$ on consumers' expenditure. Under the assumption that the weights in the objective function of Enel do not change due to interconnection, we find that easing bottlenecks would result in a saving of just over 10 million euros to the end-users of electricity in the month of May 2004, the sample period considered here. These savings account for almost $6 \%$ of spot market expenditure in the congested hours of the corresponding time period. As we do not have complete data on the costs of providing additional transmission capacity, we characterize the cost savings alone. One interesting issue is the question of optimal price differential. It is conceivable that the total welfare gain (net of costs of increasing transfer capacity) might be maximized at a point where prices are not always uniform across zones. Though a policy maker is likely to install sufficient transmission capacity so that the problem of inadequate interconnection does not reoccur in the near future, we also consider the expenditure savings for end-users accruing with "less than full" interconnection (i.e. completing resolving congestion only in a limited amount of hours). ${ }^{2}$

The industrial organization literature is rich in studies that investigate various nuances of (de)regulation in electricity markets. In a theoretical study, Borenstein et al. (2000) show that a small investment in transmission capacity can substantially improve welfare. In their analysis of Norwegian electricity markets, Johnsen et al. (2004) find that when the transmission capacity across zones binds, generators can more readily exercise market power. In this regard, the main objective of our paper is to estimate the savings associated with congestion elimination.

Market imperfections - in the sense of market price distortion (away from the first best) - are well studied in the literature. The empirical literature suggests that there is little correlation between market concentration and the degree of market power exercised by electricity generators. For example, Wolfram (1999) shows that the mark ups in the England and Wales electricity spot market in the early 1990s were lower than those implied by a Cournot duopoly model. Sweeting (2007) shows that, in the second half of 1990s, firms in the

\footnotetext{
${ }^{1}$ Limit pricing as a reasonable strategy is discussed in Section 5.2.

2 We do not consider the ownership of the transmission network and assume that the entire transmission network is under the control of a public authority. In 2004, private investment in transmission network was banned in Italy. See Joskow and Tirole (2005) for arguments against and Harvey et al. (1996) for arguments in favor of merchant transmission.
}

English electricity market exercised significant market power "in spite of decreasing market concentration". Borenstein et al. (2002) find that the presence of market power doubled the wholesale electricity price in the California's electricity market. Hortaçsu and Puller (2008) show that large generators' bids in the Texas market support the assumption of profit maximization. Another contribution this paper makes is to show that Enel does not exercise the fullest extent of its market power.

The rest of the paper is organized as follows. Section 2 describes the Italian electricity spot market. In Section 3 we present our theoretical model. Section 4 discusses our dataset and presents some summary statistics. In Section 5 we present our results along with counterfactual simulations. Section 6 presents some extensions and robustness checks. Section 7 concludes.

\section{The Italian electricity spot market}

\subsection{Market organization ${ }^{3}$}

In 2004, Italian national electricity consumption was around 322 terawatt hours (TWh), an increase of about $0.4 \%$ from the previous year. Hydrocarbons (coal, oil and natural gas) accounted for around seventy five percent of the overall installed generation capacity. Hydroelectric power plants accounted for around twenty five percent and other biofriendly generation plants (wind, photovoltaic, etc.) accounted for less than $0.5 \%$ of the total production. Nuclear energy has been banned in Italy since $1988 .{ }^{4}$ This ban, combined with a lack of any substantial competition, is often blamed for Italy's high electricity prices.

Transactions in the Italian electricity market occur both through a spot market and through individual bilateral contracts signed between the generators and the end-users. The spot market is designed to cater to the needs of the residential sector and all the industrial customers that do not sign individual contracts. It also acts as a buffer for any unanticipated short-term shocks to the demand, and operates on an hourly basis.

Residential and industrial customers are subject to two different sets of market rules. The residential sector is supplied through an intermediary (single buyer), who operates via the spot market. It accounted for more than $95 \%$ of the overall spot market quantity. Residential consumers pay a tariff set by the Italian electricity regulator (AEEG), fixed throughout Italy irrespective of zone, and subject to a quarterly review. ${ }^{5}$ Industrial spot market customers pay a weighted average of previous month's spot market clearing prices, irrespective of zone. Therefore the spot market demand can be safely regarded as independent of that day's spot market clearing prices. Hence, it is fixed for spot market considerations.

For generators, nodal pricing is in place. That is, generators participating in the spot market receive the market clearing price of the zone in which they are located. The Market Operator (MO) solicits bids from all generators each hour every day. A typical bid submitted by a generator consists of at most fourteen price-quantity combinations. A price-quantity combination is a commitment from the generator of the amount of electricity he is willing to supply at that price. The Transmission System Operator (TSO) announces the maximum amount of electricity that can be transferred across zones, which depends on several engineering criteria. The transmission network needs to undergo regular maintenance operations, thereby frequently cramping the maximum amount of electricity that

\footnotetext{
3 The market structure described here is relevant for the sample period (May 2004). In some cases market rules have changed since then.

${ }^{4}$ Roughly $60 \%$ and $15 \%$ of electricity consumption in France and Germany, respectively, are produced by nuclear power plants. In the last months of 2008 the Italian Government devised new plans to build nuclear power plants.

${ }^{5}$ The electricity price paid by the residential sector is a politically sensitive issue Therefore, though in principle it is supposed to be set as a weighted average of all the spot market clearing prices (with weights being quantities consumed), several considerations play a role during the review.
} 
can flow across zones. As a result, transmission capacity is subject to wide fluctuations across various hours, even within a single day.

Given the location of the bidding generators, their supply curves, the transmission constraint set by the TSO and the forecasted demand in each zone, the $M O$ solves the problem of optimal dispatch, whose objective is to minimize total expenditure on electricity in the spot market for a given electricity usage. The $M O$ then determines the market clearing price and quantities in each zone. All generators whose submitted bids are below the market clearing price are invited to generate the quantities they committed to in their bids.

The organization of bilateral contracts is straightforward. Contracting parties negotiate a mutually agreeable price-quantity schedule. A set of rules, representing no-arbitrage conditions, ensures that spot and contract markets can coexist and neither of them unravels. ${ }^{6}$ These contracts are private information (to the generator). For the reasons explained in Section 4, we concentrate only on the spot market. Therefore, in the rest of the analysis, the word "market" refers to the spot market alone.

\subsection{Zonal structure}

Geographically, the Italian electricity market is divided into several zones. Each zone identifies a geographical area within which the grid is almost perfect in the sense that congestion is rarely observed. The regulator defines these zones and makes frequent changes to the geographical boundaries of a zone either by joining two zones or by separating an existing zone, depending on the amount of observed congestion. In 2004, there were seven large zones, five in continental Italy (North, Center-North, Center-South, South and Calabria) and one each in the islands of Sardinia and Sicily.

In 2004, the most critical bottleneck occurred between North and Center-North (separated $48 \%$ of all hours), while Center-North and Center-South were seldom separated (around $4 \%$ of the hours) and Center-South and South were never separated.

\section{The baseline model}

In the baseline model we consider a dominant firm, Enel, facing a competitive fringe in each regional market if transmission congestion takes place, and in the integrated market otherwise. In Section 6 and in Appendix A we extend the analysis to the oligopoly case.

\subsection{Model description}

We consider the most critical bottleneck, occurring between North and Centre-North. We thus divide the market into two zones, North (above the bottleneck) and South (below the bottleneck). A Market Operator (MO) coordinates the actions of the two zones, and demand and supply conditions in the overall market. On the demand side, the price is fixed (and equal across zones) - hence the spot market demand if fully inelastic. On the supply side, the structure is similar in both zones. In each zone, there is a dominant firm, Enel, characterized by a substantial market power. Besides, there exists a competitive fringe in each zone. The assumption on the timing of the game is as follows: every hour, the Market Operator predicts the quantity demanded in the retail market and announces the same in the spot market. There is an exogenously set transmission constraint, known to all suppliers. This constraint defines the maximum amount of electricity that can be transferred across zones in the market. ${ }^{7}$ The

\footnotetext{
${ }^{6}$ Each generator for every MWh sold through bilateral contracts has to pay (receive) the difference, if positive (negative), between the average spot market price and the zonal price.

${ }^{7}$ We assume that the transfer is from North to South only. The rationale behind such assumption is two-fold. First, electricity flowing from South to North is never recorded and second, the most efficient generators are localized in the North.
}

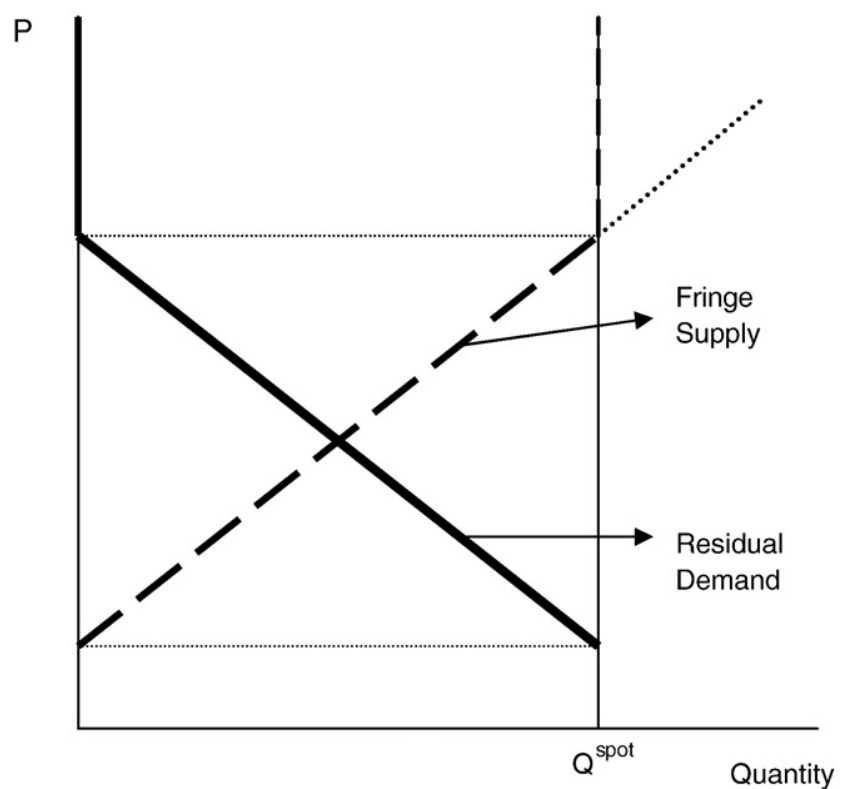

Fig. 1. Derivation of a hypothetical demand curve for Enel.

firms then place their bids consisting of price-quantity combinations. These supply curves, along with demand and supply locations, and the transmission network constraint, form the basis for the optimal dispatch algorithm explained in the previous section.

\subsection{Behavior of the fringe}

The competitive fringe consists of several firms, each of which, in turn, comprises several plants with varying efficiency levels. We assume that these plants produce their entire capacity whenever the price is above marginal cost. The dominant firm, Enel, acts as a residual demand monopolist. We assume that Enel estimates its own demand function in the following way: it estimates the supply curve of the fringe and subtracts it from the fixed demand in each zone, thereby calculating its downward sloping demand. This idea is illustrated in Fig. 1.

As the spot market price increases, more fringe generators find it profitable to employ more plants for electricity generation because the price exceeds their marginal cost. Hence, the supply curve of the fringe is upward sloping, as represented by the thick dashed line in Fig. 1 . The thin vertical line at $Q^{\text {spot }}$ represents the total electricity demanded in the spot market. The residual demand curve, obtained by subtracting the dashed line from the fixed demand, is represented by the thick downward sloping line in the picture.

For every hour each plant submits a menu of price-quantity combinations (a supply curve). We use actual bids to characterize the supply function of the fringe, thereby obtaining an estimate of the slope of Enel's residual demand $R D^{\prime}$. As the actual supply functions are step functions comprising discrete price-quantity pairs, we follow Wolak's (2003) and Hortaçsu and Puller's (2008) approach, and smooth step functions using kernel functions. Furthermore, in Section 6 , we compare our results to those obtained by using linear supply functions. ${ }^{8}$

\footnotetext{
8 The linear functional form for the supply curve simplifies computations, and guarantees the existence of a unique equilibrium. Notwithstanding its limitations, it is common in the electricity literature. See, for example, Green and Newbery (1992), Bolle (1992) and Baldick and Hogan (2006).
} 

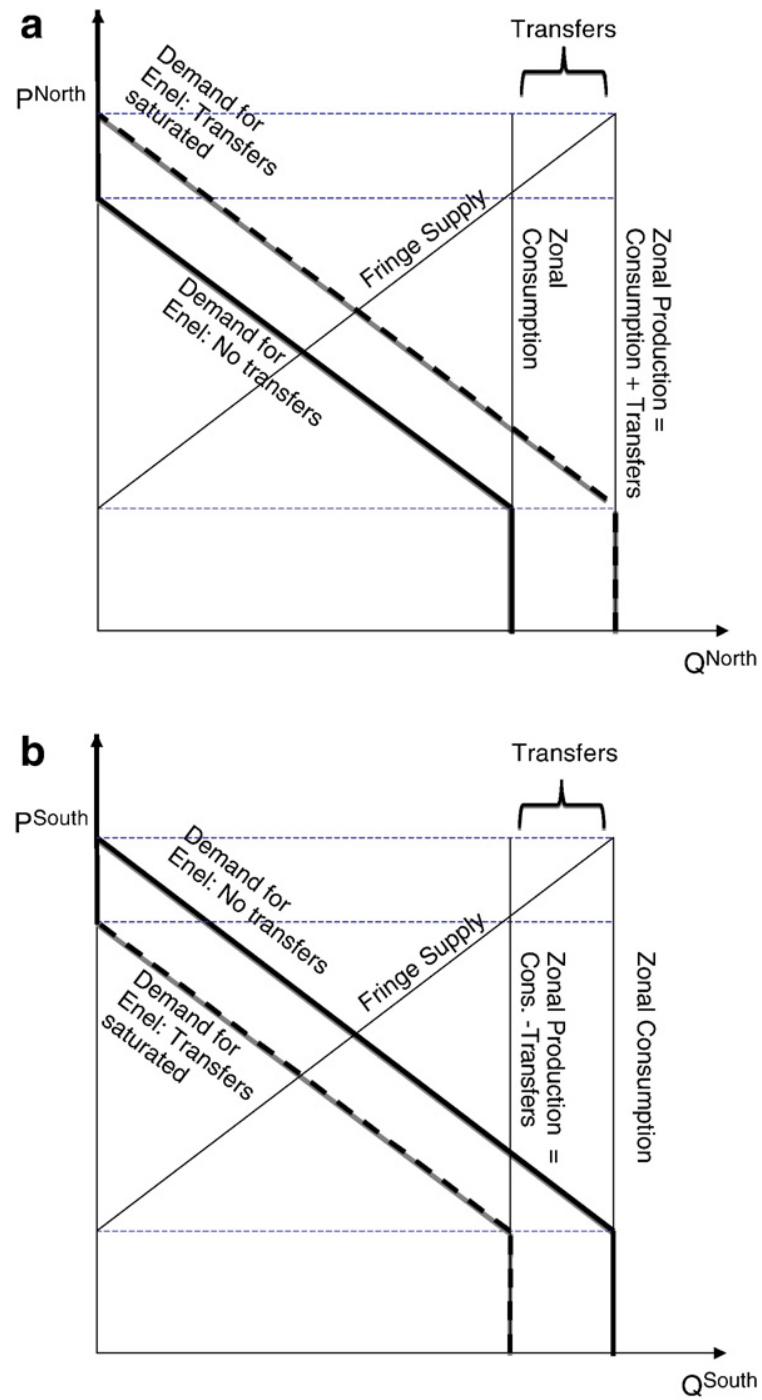

Fig. 2. Enel's demand in the two zones. (a(b) South.

For ease of exposition, suppose the fringe supply is linear. ${ }^{9}$ For each zone $z$, the quantity supplied at price $P$ at a given hour $h$ is given by:

$Q_{n, h}^{f}=\gamma_{n, h}+\beta_{n, h} P_{n, h}$

$Q_{s, h}^{f}=\gamma_{s, h}+\beta_{s, h} P_{s, h}$.

$\beta_{z, h}$ is the slope of the supply function of the fringe in zone $z$ in hour $h$, and consequently $-\beta_{z, h}$ is the slope of the residual demand function faced by Enel. ${ }^{10}$

\subsection{Behavior of Enel}

It is not unreasonable to assume that Enel, after having observed the fringe's behavior over several periods, would be able to estimate Eq. (1) and (2).

We now characterize the demand faced by Enel under limited interconnection between the markets. We call this regime $(C)$. Say the

${ }^{9}$ Section 5 below clarifies that fringe supplies and residual demands are not linear, but they both exhibit slopes that vary with $P$. In our computations, we will rely on point estimates of $\partial Q_{z, h}^{f} / \partial P_{z, h}=\beta_{z, h}$ evaluated at the market clearing prices.

${ }^{10}$ For ease of exposition, we omit here and in the subsequent formulas the subscript $d$ relative to each day.

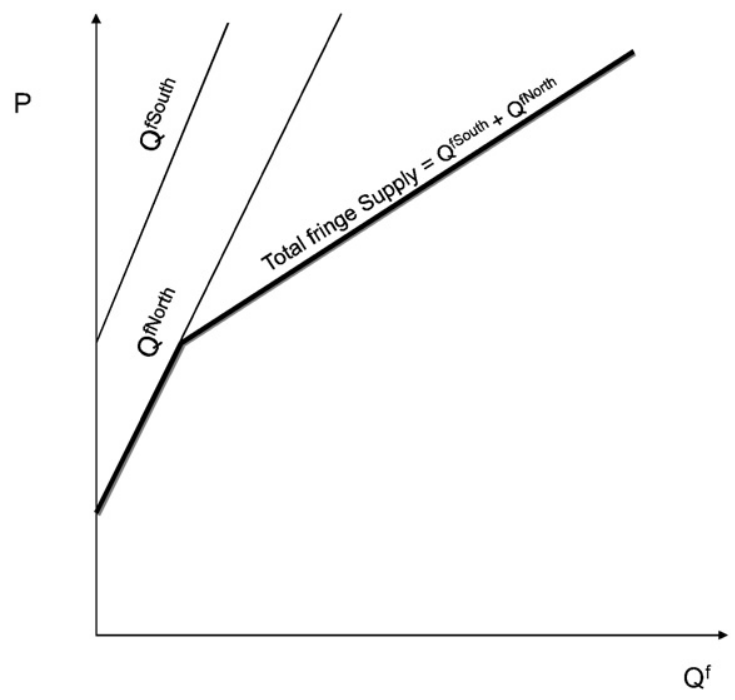

Fig. 3. Summation of fringe supply functions in the unified market.

maximum transfer capacity for hour $h$ and day $d$ is given by $T_{d, h}$. This demand function can be seen clearly in Fig. $2 a$ and $b$.

In the case where the electricity market is unified, denoted by the regime (UC), we assume that Enel is still the residual demand monopolist, albeit now for the combined demand. Also, we have separate fringes participating in the market. Total fringe supply is the summation (across quantities) of both fringes. Fig. 3 depicts the summation of the two fringe supplies, and Fig. 4 matches the aggregate fringe supply with the residual demand faced by Enel in the UC regime. As already mentioned, Enel might not behave like a profit-maximizing monopolist. Therefore the next task is to characterize the objective function of Enel.

\subsection{Objective function of Enel}

As Enel's stock in 2004 was held jointly by the Italian Treasury (around 40\%) and private investors (the remainder), we assume that its objective function is a convex combination of public incentive and profits. As the demand is inelastic, the consumer surplus theoretically is infinite. However, the change in consumer surplus is well defined, and we measure it by the change in the total expenditure on

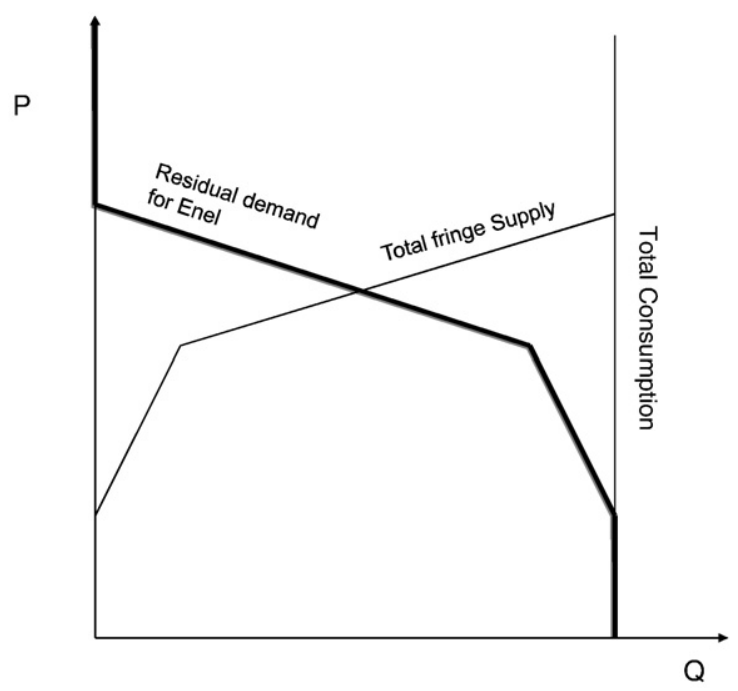

Fig. 4. Deriving the demand for Enel in the unified market. 
electricity. Let $\alpha$ be the weight given to profits. Then, the objective function of Enel for a given hour $h$ can be written as:

$\max _{P_{n, h}, P_{s, h}} \sum_{z=n, S}\left[\alpha_{z, h}\left(P_{z, h} Q_{z, h}^{\text {Enel }}-C\left(Q_{z, h}^{\text {Enel }}\right)\right)+\left(1-\alpha_{z, h}\right)\left(-P_{z, h} Q_{z, h}^{\text {spot }}\right)\right]$

$Q_{z, h}^{\text {spot }}=Q_{z, h}^{f}+Q_{z, h}^{E n e l}$ represents the overall quantity produced by Enel and by the fringe in the spot market in zone $z$.

Observe that, in modeling Enel's objective function (3), we take the bilateral (physical) contracts as given, thereby ignoring any profits from contracts. This does not hamper the identification of $\alpha$ as long as contracts market prices equal spot market prices (a no-arbitrage condition that has to hold in expectations), and as long as Enel faces the same incentives in trading off short-run profits for reduced consumer expenditure in the spot and in the contracts market. ${ }^{11}$

After having solved for the first order conditions of Eq. (3), since we have information on observed prices $P_{z, h}$ and Enel's marginal costs, and since we have estimates of $\beta_{z, h}$, we can compute the weight on profit, $\alpha_{z, h}$, by equating the predicted prices from Eq. (3) with the observed prices in the market. More precisely,

$\alpha_{z, h}=\frac{Q_{z, h}^{\text {spot }}}{Q_{z, h}^{\text {spot }}+P_{z, h} \frac{\partial Q_{z, h}^{\text {Enel }}}{\partial P_{z, h}}+Q_{z, h}^{\text {Enel }}-C^{\prime}\left(Q_{z, h}^{\text {Enel }}\right) \frac{\partial Q_{z, h}^{\text {Enel }}}{\partial P_{z, h}}}$

where $\frac{\partial Q_{z, h}^{\text {Enel }}}{\partial P_{z h}}=-\beta_{z, h}$.

We let $\alpha_{z, h}$ to be different for different periods and different zones. Indeed, in a dynamic setup, Enel could potentially consider $\alpha$ to be a variable, instead of a parameter. That is, by varying $\alpha$ strategically, one could construct a situation where a better result for the end-users can be achieved, while Enel's profits over the time horizon considered are the same (as in uniform $\alpha$ ). However, the results presented in Section 5 show that the computed $\alpha$ does not vary much across hours (the standard deviation is only 0.04).

\subsection{Evaluating counterfactual}

To estimate the savings from interconnection, we need to estimate the prices in the integrated market. For evaluating the counterfactual, we make the following assumptions. As a result of improving the transmission network: a) the behavior of the fringe does not change, and b) the objective function of Enel does not change. We compute $\alpha_{h}$ in the integrated market as the weighted average of $\alpha_{n}$ and $\alpha_{s}$.

$\alpha_{h}=\frac{\alpha_{n, h} Q_{n, h}^{\text {Enel }}+\alpha_{s, h} Q_{s, h}^{\text {Enel }}}{Q_{n, h}^{\text {Enel }}+Q_{s, h}^{\text {Enel }}}$

Therefore, the objective function in the integrated market is given by:

$$
\begin{aligned}
& \max _{P_{h}} \alpha_{h}\left[P_{h}\left(Q_{n, h}^{\text {Enel }}+Q_{s, h}^{\text {Enel }}\right)-C\left(Q_{n, h}^{\text {Enel }}+Q_{s, h}^{\text {Enel }}\right)\right]+\left(1-\alpha_{h}\right) \\
& \quad \times\left[-P_{h}\left(Q_{n, h}^{\text {spot }}+Q_{s, h}^{\text {spot }}\right)\right] .
\end{aligned}
$$

From the first order conditions, the quantity and the price in the integrated market are as follows:

$$
\begin{gathered}
P_{h}=\frac{\left(1-\alpha_{h}\right) Q_{h}^{\text {spot }}+\alpha_{h}\left(C^{\prime}\left(Q_{h}^{\text {Enel }}\right) \frac{\partial Q_{h}^{\text {Enel }}}{\partial P_{h}}-Q_{h}^{\text {Enel }}\right)}{\alpha_{h} \frac{\partial Q_{h}^{\text {Enel }}}{\partial P_{h}}} \\
Q_{h}^{\text {Enel }}=\frac{Q_{h}^{\text {spot }}-\alpha_{h}\left(\gamma_{n}+\gamma_{s}\right)+\alpha_{h} C^{\prime}\left(Q_{h}^{\text {Enel }}\right) \frac{\partial Q_{h}^{\text {Enel }}}{\partial P_{h}}}{2 \alpha_{h}}
\end{gathered}
$$

\footnotetext{
11 In any event, we would not be able to analyze the contract market explicitly due to a lack of data.
}

where $Q_{h}^{\text {spot }}=Q_{n, h}^{\text {spot }}+Q_{s, h}^{\text {spot }}, Q_{h}^{\text {Enel }}=Q_{n, h}^{\text {Enel }}+Q_{s, h}^{\text {Enel }}, \gamma_{n}$ and $\gamma_{s}$ are the intercepts of the fringe supplies and $\frac{\partial Q_{n}^{\text {Enel }}}{\partial P_{P}}=-\left(\beta_{n}+\beta_{s}\right)$ is the slope of Enel's residual demand in the integrated market. See Figs. 3 and 4.

\subsection{On the treatment of congestion}

As shown in Fig. 2a and b, the presence of transmission constraints implies a shift of the residual demand for the two zones. In surveying the approaches used to analyze the prospects for, and the impacts of, market power in electricity, Borenstein et al. (1995, p. 229) point out that: "Although there is no limit to the complexity of geographical separations that can be caused by weak lines and congestion, two cases illustrate the basic issues that can arise: (a) flow on the congested line simply acts as a shift in the demand at each end of the line, and (b) suppliers at each end strategically respond to threats of competition from suppliers at the other end". ${ }^{12}$ In case (b), the presence of kinks in the residual demand would generate non-concavities in the objective function (3). For example, Borenstein et al. (2000), in a context of two geographically separated electricity markets (each characterized by a monopoly or by a dominant firm facing a competitive fringe) with limited transmission capacity, showed that the strategic effect is such that even relatively small investments in transmission lines may be effective in spurring competition.

In our setting, Enel may have an incentive to saturate the transfer capacity with the exclusive purpose of being able to price discriminate across the two regions, while all the remaining strategic and cost considerations would point to price uniformity. ${ }^{13}$ In such cases, capacity saturation is achieved by decreasing production in the South with respect to what the other strategic and cost considerations would suggest.

Although congestion motivated by the attempts to generate price dispersion is a potential outcome, we chose not to explicitly account for it, and to consider flows on the congested line as mere demand shifters at each end of the line. While greatly simplifying the computations for the determination of $\alpha$, by ruling out issues of non-convexity, our choice is also due to two substantive reasons. First, differently from Borenstein et al. (2000), in our case the same dominant firm, i.e., Enel, lies at both ends of the congested line; therefore, the size of the transmission line does not fundamentally alter the strategic features of the game, or the nature of competition. Second, as Enel is facing a competitive fringe, its cost of altering the congestion status by decreasing aggregate production in the South increases (the required reduction in Enel's production in the South is larger, as Enel's reduction is partly compensated by production increases by the competitive fringe); as a result, Enel's incentives towards this action are reduced.

Observe that, if anything, this assumption is conservative given the main objective of the paper. If congestion induced solely by price dispersion were to be a relevant strategy for Enel, the average $\alpha$ would be overestimated. In other words, the real value of $\alpha$ would be lower than what is being estimated in our model, ${ }^{14}$ and prices in the 'but-for' market would have been lower than those computed from Eq. (7). Therefore, the gains due to interconnection are underestimated due to this assumption, and hence conservative.

\section{Data}

\subsection{Data sources}

The Italian electricity market data are collected from two sources. The primary one is the Italian Electricity Market Website. ${ }^{15}$ The

\footnotetext{
12 See also the thorough analysis of Kamat and Oren (2004) of oligopolistic electricity markets under transmission constraints.

13 We thank an anonymous referee for having raised this point.

${ }^{14}$ If our assumption were to affect the results, we would be underestimating Enel's maximal attainable profit, thereby attributing too high a weight to profits and too low a weight to Enel's concerns for consumer's welfare. As a result, $\alpha$ would be overestimated, and our results would place too much weight on Enel's profit orientation.

15 http://www.mercatoelettrico.org/GmeWebInglese/Default.aspx.
} 
Market Operator, through the website, releases information on all submitted bids one year from the time of market occurrence. The information for each bid, plant and hour consists mainly of the pricequantity pair, whether or not the bid has been accepted, and whether or not it has been cancelled. The website also reports the hourly zonal equilibrium price and quantity combinations. From these, we compute hourly price differences in the market, and identify the congested hours as those where prices differ across zones.

From the information on bids, it is straightforward to estimate the supply function of the fringe firms for every hour and every zone separately. The data on estimated marginal costs for all thermoelectric (coal, oil or natural gas based) generating plants are provided by $R e-$ searches for Economics and Finance (REF).

\subsection{Aggregation of zones}

As previously mentioned, the Italian electricity market is divided into seven large zones: North, Center-North, Center-South, South, Calabria, Sicily and Sardinia. We ignore the islands of Sicily and Sardinia for the analysis because they could be regarded as almost separate markets at the time of the analysis. For computational convenience, we further combine the remaining four zones into two zones, North and South, based on geographical proximity and frequency of bottleneck occurrences. The North zone consists of just the North, while the South zone consists of Center-North, CenterSouth, South and Calabria.

\subsection{Choice of time period}

Our analysis focuses on the month of May 2004. The choice of the month is due to the fact that saturation in transmission capacity occurs in May for $46 \%$ of the hours, a figure very close to the average value for the year $2004,48 \%$. Since the question addressed in the paper is estimating savings due to elimination of transmission congestion, May could be regarded as a representative month in terms of transmission line saturation.

Out of the thirty one days in May 2004, weekends account for ten days. We ignore weekends for the purposes of this paper because the demand is generally low, and hence the supply pattern of the fringe could be different. Moreover, the transmission constraint does not bind and hence prices are the same across zones. This information is summarized in Table 1.

On average the highest price difference occurred in hour 20 (7 P.M. to 8 P.M.) while the smallest price disparity occurred in hour 5 (4 A.M. to 5 A. M.). Quantity $\left(Q^{\text {spot }}\right)$ is always larger in the North, and peak hours are $11 \mathrm{~A}$. $\mathrm{M}$ and 5 P.M. Sample characteristics are summarized in Graphs 1 and 2.

\subsection{Analysis of bids}

To estimate the supply curve of the fringe, we consider all the bids presented by generators other than Enel. As mentioned earlier, Enel is assumed to act as a residual demand monopolist. The reason for this assumption is due to the market structure of power generators, among which Enel had clearly significant market power in 2004. There are 13 firms other than Enel, but only Edison, Endesa, Enipower and Tirreno Power have market shares beyond 2\%. Ignoring the zones of Sicily and Sardinia, Enel has $65 \%$ of the capacity ( $88 \%$ in the South

\section{Table 1}

Sample characteristics.

Source: Calculated from the data in the Italian Electricity Market website (http:// mercatoelettrico.org).

\begin{tabular}{lrlrlr}
\hline Total days & 31 & Weekend days & 10 & Weekdays $^{\text {a }}$ & 21 \\
$\begin{array}{c}\text { Total hours } \\
\text { considered }\end{array}$ & 504 & $\begin{array}{l}\text { Hours where prices } \\
\text { are the same }\end{array}$ & 195 & $\begin{array}{l}\text { Hours where } \\
\text { prices differ }\end{array}$ & 309 \\
\hline
\end{tabular}

a No other holidays in this month.

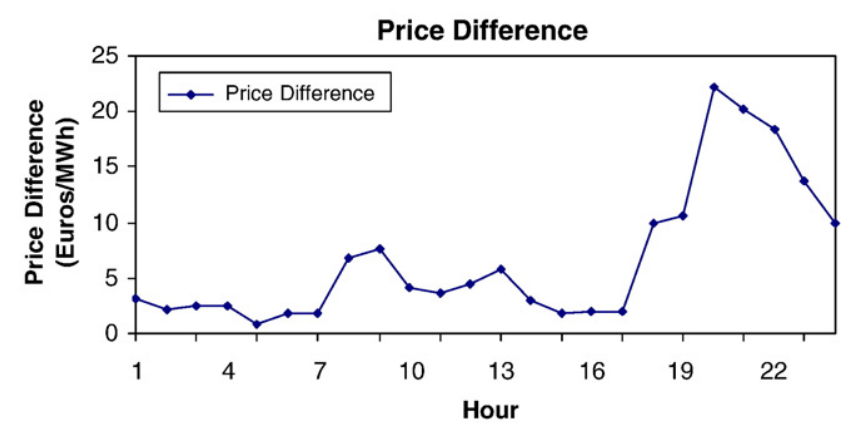

Graph 1. Average hourly price difference (price in the South-price in the North). Note: Calculated for 21 days in May 2004.

Source: Calculated from the data in the Italian Electricity Market website (http:// mercatoelettrico.org).

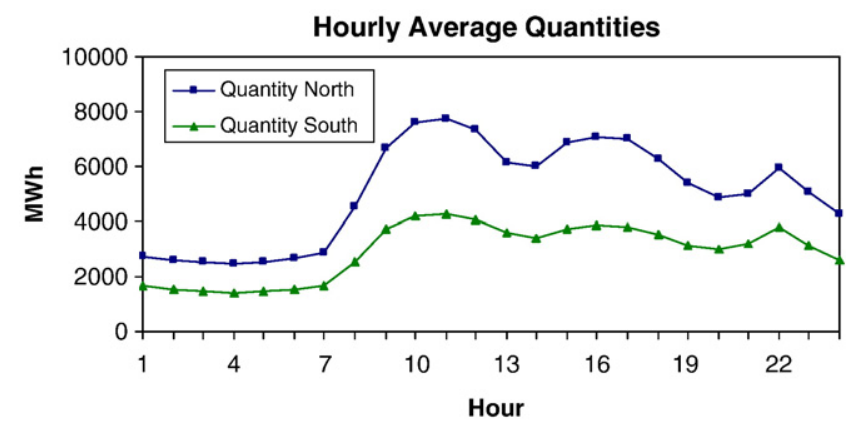

Graph 2. Zonal average hourly quantities. Note: Calculated for 21 days in May 2004. Source: Calculated from the data in the Italian Electricity Market website (http:// mercatoelettrico.org).

and $45 \%$ in the North). Moreover, only Edison is active with a market share greater than $5 \%$ in either zone. While our baseline assumption is that of a dominant firm with a competitive fringe in both zones, in Section 6 we consider also an oligopoly structure, in which Edison is assumed to behave strategically (and not like a fringe player). ${ }^{16}$

The admissible price set ranges from zero (negative bids are not allowed) to 500 euros per megawatt hour (price cap). During certain hours, generators may have an incentive to bid a price of zero for strictly positive quantities. This zero price bid ensures that the generator would be asked to produce in equilibrium, while receiving the market clearing price. By assumption, a fringe generator is not powerful enough to unilaterally influence market clearing prices. Therefore, when a generator bids a zero price for a strictly positive quantity, he merely ensures spot market participation and actually obtains a strictly positive price. ${ }^{17}$

According to the model we propose, the estimated supply function of the fringe reflects Enel's belief about the fringe firms' behavior. Considering such extreme bids would bias the estimate of $\beta$. Therefore, to avoid such a situation, we took the maximum and minimum market clearing price for every hour and constructed a "reasonable price" interval for every hour separately. The lower (upper) bound of the interval was $25 \%$ below (25\% above) the minimum (maximum) price ever realized for that hour. If the lower bound is below zero, we set it equal to zero. The maximum and the minimum prices realized every hour are given in Graph 3. Out of the remaining bids, we ignore those with a zero bid price.

\footnotetext{
${ }^{16}$ We are indebted to an anonymous referee for suggesting us this analysis.

17 If a generator has substantial commitments in the contract markets for the next hour with none at a given hour, he might find it optimal to ensure spot market participation in that hour. Significant startup costs suggest that shutting down the plant for that hour is not an economically viable option. From some informa discussions with a few fringe generators, it was evident that they have a fairly good idea of the interval in which market clearing price will be realized.
} 


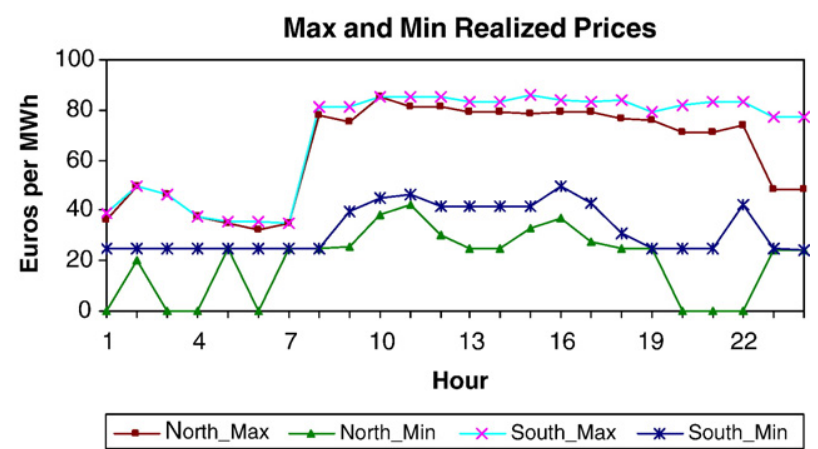

Graph 3. Maximum and minimum realized prices.

\subsection{The cost function of Enel}

Most generators are multi-plant firms. Based on the location of the plant, its production process and the inputs required for electricity generation, marginal costs for each plant may be accurately computed using engineering data. In such computations, it is assumed that the marginal cost of any given plant is constant. Since each plant has a specific efficiency level, the marginal cost of a generator is a weakly increasing function, i.e., a step function. REF provides us with engineering estimates of the marginal costs of every thermoelectric plant of Enel and of fringe suppliers. Graph 4 shows the marginal cost of Enel's thermoelectric plants. ${ }^{18}$

\subsection{Bilateral contracts versus the spot market}

In this paper we only consider the spot market and not the contracts market. The data on the contracts market are proprietary and unavailable to us. Bilateral contracts form a significant portion of electricity consumption in Italy. The details of the amount of electricity transacted in the spot market as a fraction of overall consumption, termed as liquidity, are presented in Graph 5. On average, liquidity is around 30\%.

The Italian contracts are mostly bilateral physical contracts and not just the financial instruments (hedge contracts) previously addressed in the literature (see Wolak, 2000). A retailer/generator who signs the contract is expected to physically deliver electricity to the consumer involved in the contract at a pre-determined and mutually agreed price. ${ }^{19}$ From the few contracts we have obtained, the price agreed upon is often a weighted average of the previous month's spot market clearing price (implying that in expectations consumers are indifferent between contracts and spot markets). Therefore, assuming this as a general rule, our estimate of expenditure reduction triggered by interconnection is conservative.

The contract market plays a role in determining the 'marginal plant' Enel uses for production in the spot market. As honoring bilateral contracts is mandatory, while participation in the spot market is not, any given generator uses its most efficient plants to supply the contract market. Therefore it becomes crucial to determine the marginal plant, i.e., the most efficient plant employed in the spot market. The method with which we identify the marginal plant in the unintegrated regime is as follows. We manually identify, using data on bids and marginal cost, the most efficient of Enel's plants that participated in the spot market for every hour and every zone, and we labeled it the marginal plant for that hour for that zone. We also assume that all plants whose marginal cost is below the marginal plant participate exclusively in the contracts markets. Further, the

\footnotetext{
18 Excluding Sicily and Sardinia, we considered 70 thermoelectric plants owned by Enel (45 in the North and 25 in the South). The step cost functions for the other generators are similar. For example, Edison has 19 plants of which 12 are localized in the North. Edison's marginal costs range from 27 to 50.4 euros (the latter are attained at an aggregate capacity of $4454 \mathrm{MWh}$ ).

19 The Italian law forbids generators from signing bilateral contracts directly. These generators operate in long-term contracts market via affiliated retailers.
}

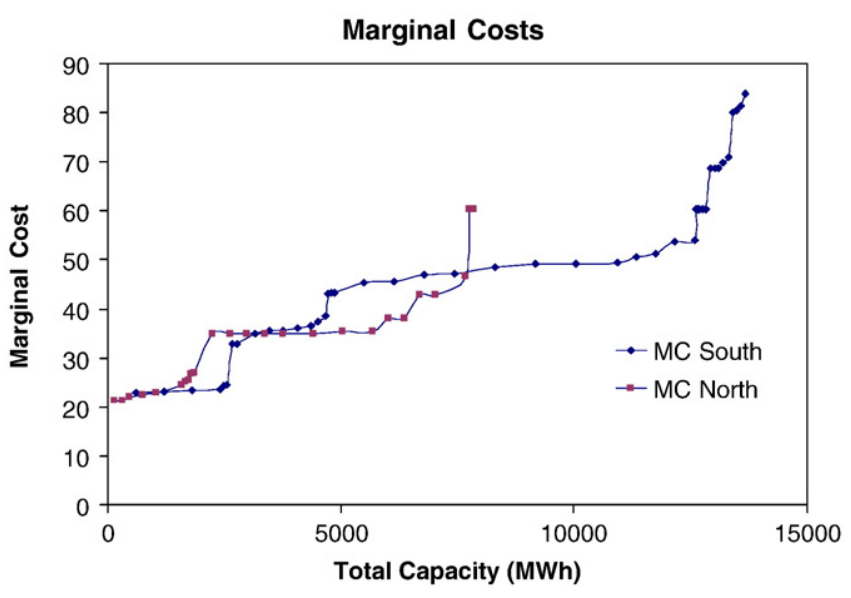

Graph 4. Enel's marginal costs for North and South. Source: Proprietary dataset from REF.

marginal plant and all those with higher marginal cost bid exclusively in the spot market.

In order to determine the marginal plant in the unified market (i.e., the counterfactual), we assume that the market share of Enel in the contracts market is equal to its share in the spot market. This assumption allows us to roughly predict the amount of electricity that needs to be generated by Enel for the contract market. By arranging Enel's plants in decreasing order of efficiency (increasing order of marginal cost), it is straightforward to identify the marginal plant under the assumption that the most efficient plant(s) participate(s) in the contract market. The identification of marginal plants comes at a cost. The method described above implicitly assumes there are no plant shut-downs and start up costs. It also fails to take into account any network imperfections within a zone. Therefore, our predicted expenditure savings could be overstated.

\section{Results}

\subsection{Supply functions of the fringes}

As discussed in Section 3, we follow Wolak (2003) and Hortaçsu and Puller (2008) and smooth step functions in the data using a nonparametric (Kernel density) regression estimation to estimate $\beta_{\text {north, } h}$ and $\beta_{\text {south, } h}$ and consequently to obtain the slope of the residual demand function $R D^{\prime}$.

Let the fringe supply function for zone $z$ for hour $h$ be represented by the pairs $\left\{\left(P_{1}, Q_{1}\right) \ldots,\left(P_{n}, Q_{n}\right)\right\}$. The smoothed version of this function will be

$Q^{f}=\sum_{i=1}^{n} Q_{i} K\left(\frac{P-P_{i}}{\theta}\right)$

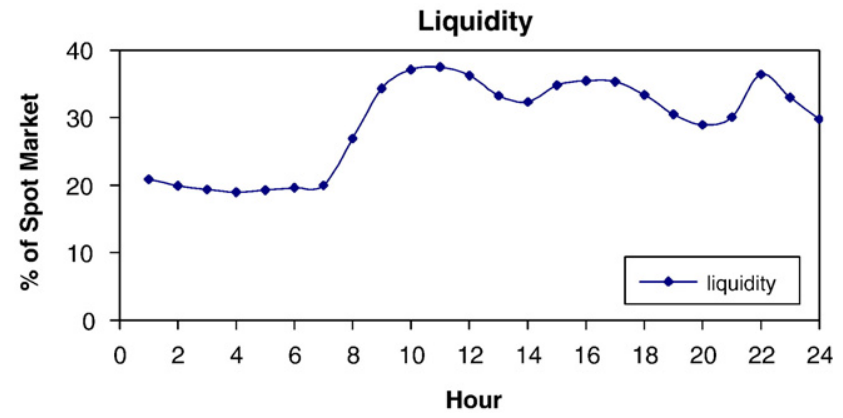

Graph 5. Hourly average liquidity. Source: www.mercatoelettrico.it. 
Slopes from Kernel Density Regression Estimation

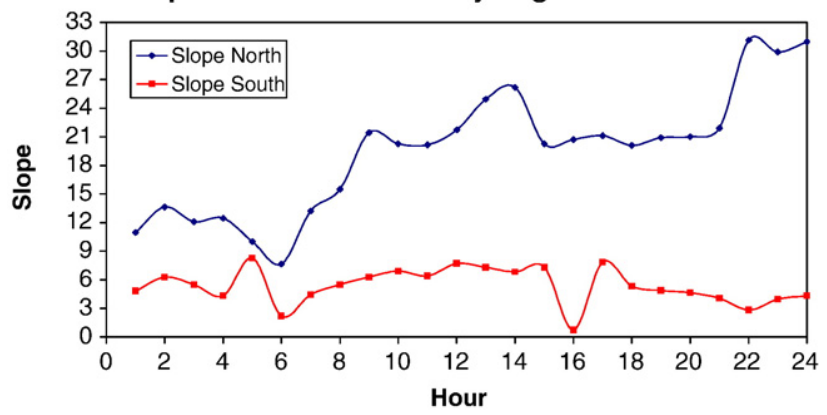

Graph 6. Estimated $\beta^{\prime} \mathrm{s}^{\mathrm{a}}$. a Average values of $\beta_{n, h}$ and $\beta_{s, h}$ computed from Eq. (10) evaluated at the market clearing prices $P_{z, h}$.

where $K(\cdot)$ is a kernel function and $\theta$ is the smoothing or bandwidth parameter. The derivative of the supply function is given by:

$Q^{f^{\prime}}(P)=\frac{\partial Q^{f}}{\partial P}=\sum_{i=1}^{n} Q_{i} \frac{1}{\theta} K^{\prime}\left(\frac{P-P_{i}}{\theta}\right)$.

$\frac{\partial Q^{f}}{\partial P f}$ is an estimate of the slope $\beta_{z, h}$ of the fringe's supply function in zone $z$ in hour $h$ which clearly varies with $P$. Since we need a point estimate of $\beta_{z, h}$ for each zone/hour/day triplet, we evaluated Eq. (10) at the market clearing prices.

Graph 6 presents the average values for $\beta_{n, h}$ and $\beta_{s, h}$ for every hour across all days. ${ }^{20}$ Since data inspection indicates that the fringe has a larger presence in the North than in the South, one should find Enel to be more responsive to prices in the North than in the South. Graph 6 clearly shows that, as expected, the slopes of the fringe supply in the North are larger than in the South for all hours.

\subsection{Enel's objective function}

Before simulating the market under the alternative market regime of no transmission constraint, we characterize the objective function of Enel as described in Section 3. Enel places a weight $\alpha$ on profit and $1-\alpha$ on consumer welfare. We compute $\alpha$ for every hour by equating observed prices in both zones with the prices predicted from the first order conditions of the objective function (3). We compute the overall $\alpha$ in the integrated market as a weighted average of $\alpha_{n}$ and $\alpha_{s}$. Characteristics of computed $\alpha$ are presented in Table 2. On average $\alpha$ takes the value 0.66 with a low standard deviation of 0.04 . Such results are comforting, taking into account the fact that in 2004 around $60 \%$ of Enel was owned by private investors and around $40 \%$ by the Italian treasury. The weight on profits is higher in the North and lower in the South.

Given Enel's estimated relative weights on profit and on consumer surplus (reflecting its actual relative concerns on the two components), their heterogeneous distribution across zones may be consistent with strategies aimed both at deterring prospective entry through limit pricing, and at appeasing the regulator, probably for fear that a relevant price difference may be perceived as the result of market power exploitation, and thus may lead to regulatory retaliation. ${ }^{21}$ In fact data suggest that Enel aligns (by selecting an appropriate pair of $\alpha_{n}$ and $\alpha_{s}$ ) the prices between the North and the

\footnotetext{
${ }^{20}$ We used a total of 22,403 actual bids (19,208 placed in the North and 3195 placed in the South). The minimum number of observations is 45 (hour 5 in South) and the maximum number of observations is 1273 (hour 22 in North). See Boffa and Pingali (2006) for further details. We used a normal kernel density and the smoothing parameter $\theta=1$.

${ }^{21}$ A political economy story, according to which Enel's behavior reflects an incentive to favor Southern consumers and firms, can be dismissed if one considers that the price consumers pay is invariant across zones (it is a weighted average of zonal prices received by the producers in the various zones).
}

Table 2

Characteristics of $\alpha_{z, h}$

\begin{tabular}{lll}
\hline & $\alpha_{n, h}$ & $\alpha_{s, h}$ \\
\hline Min & 0.57 & 0.54 \\
Max & 0.98 & 0.73 \\
Median & 0.68 & 0.62 \\
Average & 0.69 & 0.63 \\
Standard Deviation & 0.07 & 0.04 \\
& & \\
\hline Simple average & $\alpha_{z, h}$ & \\
Standard Deviation & 0.66 & \\
& 0.06 & \\
& & \\
\hline Weighted average & $\alpha_{h}$ & \\
Standard Deviation & 0.66 & \\
\hline
\end{tabular}

Weights given by Enel's spot market production for the hour.

Note: Calculated for all hours where price difference is non-zero.

South, probably for one of the two above mentioned reasons. ${ }^{22}$ Observe that, given the specific nature of Enel's objective function, it may well be that $\alpha$ represents a credible commitment and therefore limit pricing could be a viable strategy. ${ }^{23}$

\subsection{Simulations in the alternative market}

After characterizing the objective function of Enel, we simulate the market under the alternative market structure of no transmission congestion.

We employ an iterative procedure to obtain the equilibrium in the integrated market regime. First, we identify the marginal plant in the interconnected market using the method discussed in Section 4.6. Then, we order Enel's plants that participate in the spot market in a decreasing order of efficiency. Later, we calculate the objective function-maximizing output for the most efficient plant ignoring the plant's generation capacity constraint. If that output is feasible (i.e. lower than the plant's generation capacity), it is the equilibrium quantity. Otherwise, we consider the two most efficient plants and reiterate the process.

We present simulated prices and quantities in Graphs 7 and 8 respectively. Hourly average prices in the integrated market are well below the average prices in the South and are very close to the prices in the North. In other words, while North almost maintains its status quo (with small price increases), South is benefited substantially with lower prices in regime UC. Graph 8a) shows that, under the $C$ regime, on average, 1396 MWhs of electricity are transferred, and transfers represent on average $16 \%$ of total spot market production (47\% of average production in the South). Graph $8 \mathrm{~b}$ ) shows that in the integrated market (UC regime) the quantity produced by Enel slightly increases at the expense of the production of the competitive fringe. Transfers increase as well, especially in the last $6 \mathrm{~h}$. Enel's market share increases from $56.5 \%$ to $57.3 \%$, and transfers increase on average by $51 \mathrm{MWhs}(+6 \%)$. The maximum increase in transfers is $446 \mathrm{MWhs}$ (+50\%).

The simulation results indicate that market integration significantly reduces consumer expenditures. The overall expenditure reduction is above ten million euros for May 2004. Under the assumption that May is

\footnotetext{
22 To be more specific, this "redistribution" across zones does not affect consumers (who pay anyway an average price irrespective of the zone in which they are located), and becomes irrelevant in the integrated market. However, as long as the market remains unintegrated, a low alpha in a certain region may be reflective of other concerns (such as limit pricing or appeasing the regulator by aligning the prices in the two zones).

${ }^{23}$ The usual argument that under observability of marginal cost limit pricing is not credible, should not apply in this environment due to the concerns for consumer surplus.
} 


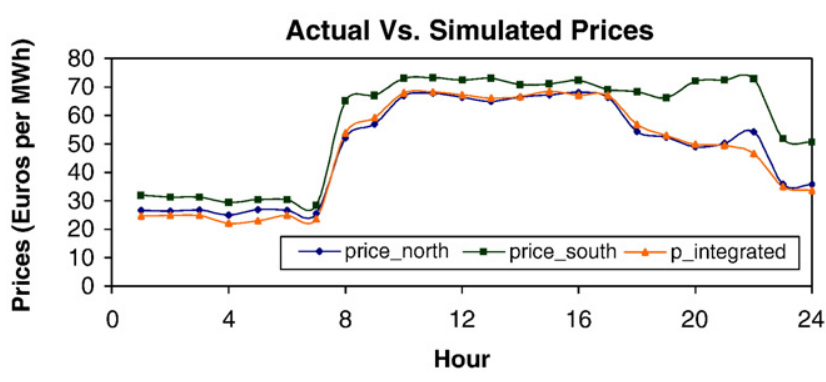

Graph 7. Simulated versus actual prices. Note: Calculated for all hours where prices in the North and the South are different.

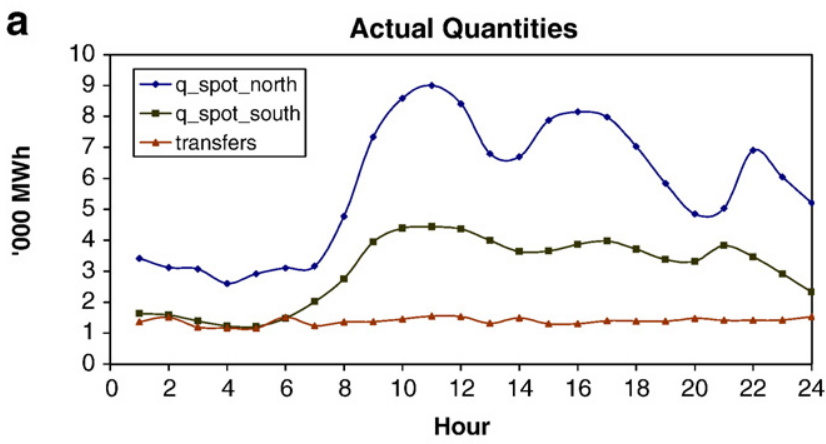

b

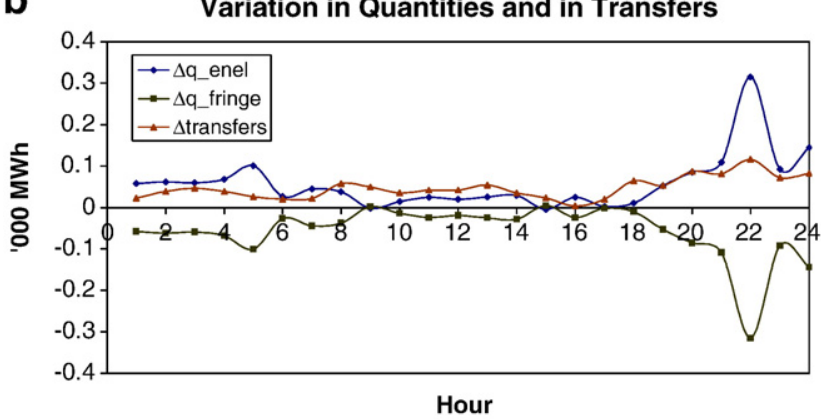

Graph 8. Simulated versus actual quantities. Note: Calculated for all hours where prices in the North and the South are different.

a representative month, the expenditure reductions can be estimated to be over 120 million euros for 2004. Savings from interconnection are summarized in Graph 9. The maximum gain for end-users is observed in hour 22 (9 PM to 10 PM) on 31 May 2004.

While, as discussed in Section 3.6, we do not introduce any strategic considerations à la Borenstein et al. (2000), we find results that are consistent with the "thin line" argument: considerable savings can be attained also under partial interconnection (i.e. when the transmission capacity is increased by less than 446 MWhs), due to the increased scope for utilization of the most efficient generating plants. $^{24}$ The last column of Table 3 shows that savings from interconnection do not increase linearly with the addition of transmission capacity: a $50 \mathrm{Mwh}$ transmission line leads to a 5 millions savings, an increase of 150 MWhs is sufficient to obtain savings equal to 8.5 million euros, and most of the savings (91\%) can be obtained by allowing an extra 200 MWhs to flow across the two regions. In particular, the third column reports the cost savings that can be attained in the hours in which the new transmission capacity is

\footnotetext{
${ }^{24}$ We thank an anonymous referee for having raised this issue.
}

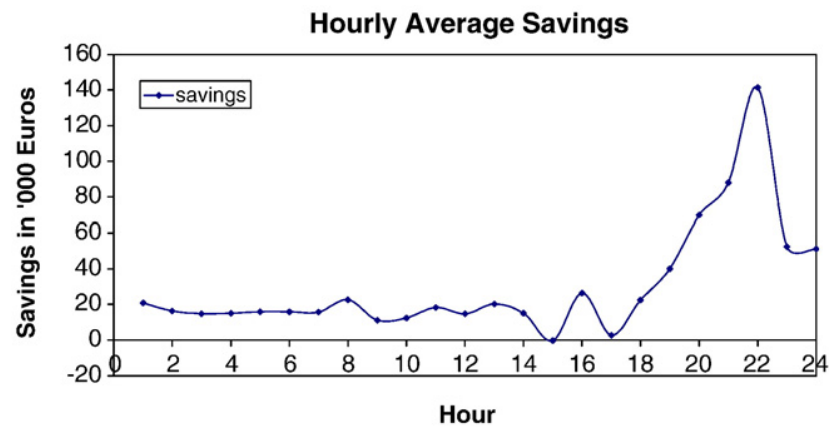

Graph 9. Hourly average savings. Note: Calculated for all hours where price difference between zones is not zero.

enough to completely resolve congestion, while the second column reports the cost savings for the remaining hours $h_{c}$ for which the investment is not sufficient to fully remove the bottleneck, so that the two markets remain geographically separated. For such hours, using the weights $\alpha_{z, h}$ on profits computed in Section 5.2, we employ the first order condition of Eq. (3) and solve Eq. (4) to simulate the prices $P_{n, h c}$ and $P_{s, h c}$ that would prevail under zonal pricing. In so doing, we increase $Q_{n, h c}^{\text {spot }}$ by the amount of the investment in new transmission capacity $\Delta T_{h}$, and we reduce $Q_{s, h c}^{\text {spot }}$ accordingly (see Fig. $2 \mathrm{a}$ and b). ${ }^{25}$

\subsection{Overall effects of integration}

In this paper we focus our attention on the variation of consumer surplus. In order to develop a full welfare analysis one should be able to include the change in producers' surpluses, the cost of building additional transmission capacity, as well as environmental costs and the opportunity costs incurred due to possible disturbances to the existing transmission network. ${ }^{26}$

As to the costs of increasing interconnection, in 2004, the owner of the Italian infrastructure responsible for interconnection - Terna estimated that it would cost around four hundred thousand euros of labor and material cost per kilometer of interconnection. Though the actual bottleneck occurs only for around one hundred kilometers, and hence the cost would be forty million euros, an improved inter-zonal transmission network also requires a more efficient intra-zonal transmission mechanism, the cost of which we have no data on. On the other hand, the "thin line" argument developed above could imply that, after an appropriate and thorough cost to benefit analysis, the optimal solution could prescribe a partial increase in the transmission capacity.

By including the producers' surplus into the analysis, one can notice that in the short run the net welfare change is driven by the reduction in production costs after eliminating congestion, ${ }^{27}$ while expenditure reduction is primarily due to a transfer from producers to consumers. However, the decline in total expenditure triggered by interconnection uncontroversially leads to a welfare improvement in

\footnotetext{
25 As discussed in Section 3.6, we ignore Enel's strategies involving transfer saturations that occur for the pure incentive towards price dispersion. As compared to the actually observed ones, prices increase in the North and reduce in the South but, as reported in the second column of Table 3, due to the relatively more efficient use of generating plants in the North, the net effect points towards the presence of cost savings.

26 Therefore, keeping into account the additional fact that more than one month of data on bids, observed prices and quantities would be required, a full cost benefit analysis is beyond the scope of the present paper.

27 To that respect, our data show that there were hours where Enel's plants in the North with marginal cost less than twenty seven euros were idle, while in the South plants with marginal cost more than forty euros were in operation. Therefore Enel has a chance to reorganize its production plans and reduce its total costs. But this is accomplished at the expense of fringe suppliers' profits.
} 
Table 3

Interconnection gains and transmission capacity.

\begin{tabular}{llll}
\hline $\begin{array}{l}\text { Increase in } \\
\text { transmission } \\
\Delta T_{h} \text { (MWhs) }\end{array}$ & $\begin{array}{l}\text { Expenditure savings (still) congested } \\
\text { hours (euro) }\end{array}$ & $\begin{array}{l}\text { Expenditure savings } \\
\text { from full } \\
\text { interconnection (euro) }\end{array}$ & $\begin{array}{l}\text { Total expenditure } \\
\text { savings from } \\
\text { interconnection (euro) }\end{array}$ \\
\hline 50 & 321,606 & $4,737,454$ & $5,059,060$ \\
100 & 414,185 & $6,349,456$ & $6,763,641$ \\
150 & 259,721 & $8,252,475$ & $8,512,196$ \\
200 & 130,148 & $9,303,145$ & $9,433,293$ \\
300 & 127,134 & $9,474,095$ & $9,601,229$ \\
446 & - & $10,275,532$ & $10,275,532$ \\
\hline
\end{tabular}

medium and long runs, where demand elasticity is larger due to the emergence of potential substitution patterns. ${ }^{28}$

\section{Robustness and extensions}

In this section we test the robustness of our results to alternative estimation methods for $\beta$ 's and, most importantly, to an alternative (oligopolistic) hypothesis about the market structure.

\subsection{Linear fringe supply functions}

Instead of following the step function approach, one can simply assume that the supply curve is linear. While this assumption is clearly restrictive, it simplifies computations, and guarantees the existence of a unique equilibrium.

Eqs. (1) and (2) are now represented by

$Q_{n, d h}^{f}=\gamma_{n, h}+\beta_{n, h} P_{n, d h}+\theta_{n, d}+\varepsilon_{n, d h}$

$Q_{s, d h}^{f}=\gamma_{s, h}+\beta_{s, h} P_{s, d h}+\theta_{s, d}+\varepsilon_{s, d h}$

where $\theta_{z, d}$ indicates day fixed effects, and $\varepsilon_{z, d h}$ is the idiosyncratic error for zone $z$. Eqs. (11) and (12) have been estimated by using fixed effects (FE) and random effects (RE). ${ }^{29}$

The results of various estimation methods, and the comparisons with the Kernel Density Regression Estimation are presented in Table 4. Estimated $\alpha$ 's are very similar, while estimated $\beta$ 's are lower for the Kernel Regression in both zones. Prices in the interconnected market range from 50 to 51.6 and savings from interconnections range from 9.1 to 10.9 million euros. ${ }^{30}$

\subsection{Oligopoly structure}

In the baseline model, Enel is assumed to be the only firm with market power. In this subsection we extend our analysis to the oligopoly case. Borenstein et al. (2000) modelled the California's electricity market at the time of deregulation, early in 1998, as divided in two distinct regional markets. In each zone a dominant firm (Pacific Gas \& Electric with a 60\% market share in the region North of the Path

\footnotetext{
${ }^{28}$ Notice also that, given the form of its objective function, Enel takes advantage from a reduction in consumer expenditure triggered by the additional interconnection, and might therefore have an incentive to invest in new transmission capacity.

29 As there are several factors that could influence the fringe firms' bids on a given day, it is likely that their bidding pattern is different across days. Any supply function estimation that does not take into account such differences - as in the case of OLS estimation - is likely to create a bias in the estimates of the slope parameters.

${ }^{30}$ For more details on the estimation of a linear fringe supply, see Boffa and Pingali (2006), who also considered the empirical shortcut of estimating a linear marginal cost function for Enel. Finally, we also tried to estimate the fringe supplies by using data on observed quantities and market clearing prices, i.e. without using actual bids (see Bushnell et al., 2008, who have tested different functional forms). Results are qualitatively similar, but the implied reduced variability of point estimates of the residual demands slopes yields a $10 \%-15 \%$ reduction in cost savings due to interconnection.
}

Table 4

Comparison across estimation methods.

\begin{tabular}{lccc}
\hline & Kernel & Random effects & Fixed effects \\
\hline Average $\beta^{\text {a }}$ in North & 21.25 & 22.52 & 22.64 \\
Average $\beta^{\text {a }}$ in South & 5.41 & 5.90 & 5.90 \\
Average $\alpha$ in North & 0.693 & 0.690 & 0.700 \\
Average $\alpha$ in South & 0.629 & 0.627 & 0.627 \\
Price with interconnection (euro/MWh) & 51.04 & 51.55 & 50.04 \\
Savings from interconnection for & 10.28 & 9.09 & 10.93 \\
$\quad$ May 2004 (million euro) & & & \\
\hline a Average values across the 24h. & & &
\end{tabular}

15 transmission constraint and Southern California Edison with $45 \%$ in the Southern region) was facing a competitive fringe. ${ }^{31}$ In a recent work, Puller (2007) modelled the Californian electricity market in the post-divestiture years (1998-2000) as a unified market with the 5 largest firms ${ }^{32}$ acting as strategic players and the remaining ones as part of the competitive fringe.

The Italian market structure in 2004 resembles closely to the Californian one at the time of deregulation, with the substantial exception that the dominant player is Enel in both regional markets ( $88 \%$ of capacity in the South and $45 \%$ in the North). This is why we believe in a monopolistic industry structure, which we analyse in our baseline model. However, we have also explored the implications of an alternative assumption involving a duopolistic structure. In this model, Enel and Edison play a Cournot game facing a competitive fringe in both zones as well as in the integrated market. ${ }^{33}$ The details of the model are reported in Appendix A.

At first, we estimated a new fringe supply that excludes Edison's bids ${ }^{34}$ and thus obtain the new slopes of the residual demand function $\left(\frac{\partial Q_{z h}^{r}}{\partial P_{z, h}}=-\beta_{z, h}^{\prime}\right)$. Second, from the first order conditions for the Cournot model we estimate the new weight $\alpha_{z, h}^{\prime}$ attributed to profits in Enel's objective function.

$$
\alpha_{z, h}^{\prime}=\frac{Q_{z, h}^{\text {spot }}}{\gamma_{z, h}^{\prime}+Q_{z, h}^{\text {Edison }}+2 Q_{z, h}^{\text {Enel }}-C^{\prime}\left(Q_{z, h}^{\text {Enel }}\right) \frac{\partial Q_{z, h}^{r}}{\partial P_{z, h}}}
$$

From the first order condition for Edison, its best response function obtains:

$Q_{z, h}^{E d i s o n}=\frac{Q_{z, h}^{\text {spot }}-Q_{z, h}^{E n e l}-\gamma_{z, h}^{\prime}-C^{\prime}\left(Q_{z, h}^{E d i s o n}\right) \beta_{z, h}^{\prime}}{2}$

Eq. (14) can be used to obtain simulated values of $Q_{z, h}^{\text {Edison }}$ to be compared with the observed actual quantities in order to verify the plausibility of the duopoly assumption.

In the integrated market, assuming an average value of $\alpha^{\prime}$, and solving for the optimal quantities of $Q_{h}^{\text {Enel }}$ and $Q_{h}^{\text {Edison }}$, it is possible to estimate the prevailing price as follows:

$P_{h}=\frac{\left(1-\alpha_{h}\right) Q_{h}^{\text {spot }}+\alpha_{h}\left(\left[C^{\prime}\left(Q_{h}^{\text {Enel }}\right)+C^{\prime}\left(Q_{h}^{\text {Edison }}\right)\right] \frac{\partial Q_{h}^{r}}{\partial P_{h}}-\left(Q_{h}^{\text {Enel }}+Q_{h}^{\text {Edison }}\right)\right)}{2 \alpha_{h} \frac{\partial Q_{h}^{r}}{\partial P_{h}}}$

\footnotetext{
31 Borenstein and Bushnell (1999) developed a simulation model which included also San Diego Gas \& Electric as a further strategic player in a unified (i.e. by assuming the absence of transmission constraints) model of the California's electricity market.

32 AES, Reliant, Duke, Southern and Dynegy were broadly of the same size and were responsible for $50 \%$ of the total generation capacity.

${ }^{33}$ Still excluding Sicily and Sardinia, Edison market share was 21\% in the North and $5 \%$ in the South (13.5\% overall), while the third biggest player, Endesa was operating only in the North with a market share of $17 \%$ ( $9 \%$ in the whole market). All the other players (among which Enipower and Tirreno) had market shares below 5\%.

34 The total number of observations is now 17,803 (15,094 bids placed in the North and 2709 bids placed in the South).
} 
Table 5

Actual figures versus oligopoly simulations.

\begin{tabular}{|c|c|c|c|c|}
\hline & \multicolumn{3}{|l|}{ Prices } & \multirow{2}{*}{$\begin{array}{l}\text { Consumer } \\
\text { expenditure } \\
\text { (million euro) }\end{array}$} \\
\hline & North & South & Integrated market & \\
\hline \multicolumn{5}{|l|}{ Actual data } \\
\hline Actual prices (euro/MWh) & 51.44 & 56.57 & - & 166.6 \\
\hline \multicolumn{5}{|l|}{ Simulated data } \\
\hline $\begin{array}{l}\text { Dominant firm in } \\
\text { integrated market }\end{array}$ & - & - & 51.04 & 156.3 \\
\hline $\begin{array}{l}\text { Duopoly with fringe } \\
\text { in both zones }\end{array}$ & 47.59 & 54.02 & - & 147.8 \\
\hline $\begin{array}{l}\text { Duopoly with fringe } \\
\text { in integrated market }\end{array}$ & - & - & 47.39 & 141.4 \\
\hline
\end{tabular}

where $\frac{\partial Q_{h}^{r}}{\partial P_{h}}=-\left(\beta_{\text {north }}^{\prime}+\beta_{\text {south }}^{\prime}\right)$ is the slope of the residual demand in the integrated market.

The estimated values of $\alpha_{n, h}^{\prime}$ and $\alpha_{s, h}^{\prime}$ turn out to be on average slightly higher as compared to the baseline model (0.698 and 0.631, respectively). This is consistent with the intuition that, given the observed prices $P_{z, h}$, in a more competitive environment Enel should put more weight on profits.

Table 5 shows that in the integrated market the price would fall down to 47.39, and the total consumer expenditure would reduce from 166.6 to 141.4 million euro, implying a total saving of 25 million euros. The oligopoly model, however, is an accurate representation of reality only if the actual market data prove to be compatible with the model prediction. In fact, by comparing the estimated values of $Q_{z, h}^{\text {Edison }}$ resulting from Eq. (14) to the actual values produced by Edison, we record large differences, especially in the hours with low demand (during the night and early in the morning). Also, the average differences between the actual supply of Enel and estimated values of $Q_{z, h}^{\text {Enel }}$ are higher with respect to the baseline case.

An alternative intuition for this is provided by looking at Eq. (19) in Appendix A. By considering the estimated values of $Q_{z, h}^{E d i s o n}$ and $Q_{z, h}^{\text {Enel }}$, it is possible to estimate the prices that would prevail in an oligopoly setting and compare them to the actually observed ones. Our results show that observed prices in the two zones are rather different than the expected ones (47.59 euros in the North and 54.02 euros in the South). The simulated total expenditure is 147.8 million euros (smaller than the actual expenditure of 166.6 million euros), and the savings due to interconnection are 6.4 million euros.

These figures are reported in Table 5, which compares the results of our baseline model (the first two rows) with those stemming from the duopoly simulation (last two rows).

Observe that the reduction of consumer expenditures under full interconnection is higher (10.3 million euros) if the starting point is a market structure with a dominant firm and a competitive fringe than under a duopoly facing a competitive fringe (6.4 million euros). A possible intuition for the result is that the benefits from Enel's plants reshuffling are harder to achieve under the additional constraint imposed by Edison's strategic behavior.

\section{Conclusion}

The paper analyzes the benefits for end-users associated with eliminating transmission bottlenecks across zones in the Italian electricity spot market.

The simulation of such benefits requires knowledge of the objective function of Enel, the major generator in the market. There are many reasons to believe that mere short-run profit maximization does not apply to Enel. Our results confirm that the expenditure minimization is a significant component of Enel's objective function. In particular, we find that Enel associates a weight of $66 \%$ to short-run profits and the remaining $34 \%$ to expenditure minimization. The incentives towards expenditure minimization may stem either from long-run profit considerations (related to the need to prevent regulatory retaliation and entry), or from State ownership and orientation to consumer surplus. Under the assumption that these weights do not change after the elimination of the transfer constraints, we find that the total expenditure savings to the endusers under the complete elimination of transmission bottlenecks would be more than ten million euros in the month of May 2004, our sample period. These savings are driven by the reshuffling of production across plants by Enel, that in the interconnected market can better exploit the most efficient generation units in the North, as well as by a transfer from producers to end-users. Since May can be regarded as a representative month in terms of the saturation occurrence rate, we may speculate that yearly expenditure saving to end-users in the spot market would amount to more than 120 million euros. There are reasons to believe that a no-arbitrage condition would ensure that the contracts market would - at least partially match the spot market in terms of price reduction.

Moreover, our analysis shows that savings are not a linear function of the size of new transmission lines. Even a relatively small increase in the interconnection capacity - a thin line - can be effective in reducing prices and bringing benefits to electricity consumers.

Such results are based on the assumption that Enel is a dominant player that faces a competitive fringe in both zones. We also extend our analysis to include the possibility that the second largest producer on the Italian spot electricity market, Edison, is a strategic player, and find that the observed prices do not support the duopoly assumption. While data constraints prevent us from developing a full welfare analysis, our results show that improving market interconnection is substantially increasing consumer surplus in the short run (when electricity demand is rigid), and is very likely to have important total welfare effects in the long run (when demand is elastic and price reductions per se display an efficiency-enhancing effect beyond the mere transfer from producers to consumers).

\section{Appendix A. Oligopoly structure}

Differently from the baseline model, in which a dominant firm faces a competitive fringe in both zones, we consider now the case of two asymmetric firms, Enel and Edison, facing the residual demand by playing a quantity game. In the separated markets case, Enel's objective function is

$\max _{Q_{n, h}, Q_{s, h}} \sum_{z=n, s}\left[\alpha_{z, h}\left(P_{z, h} Q_{z, h}^{\text {Enel }}-C\left(Q_{z, h}^{\text {Enel }}\right)\right)+\left(1-\alpha_{z, h}\right)\left(-P_{z, h} Q_{z, h}^{\text {spot }}\right)\right]$

and the residual demand function (denoted with $Q_{z, h}^{r}$ ) faced by the two oligopolists after subtracting the fringe production is:

$Q_{z, h}^{r}=Q_{z, h}^{\text {Enel }}+Q_{z, h}^{\text {Edison }}=Q_{z, h}^{\text {spot }}-Q_{z, h}^{f}=Q_{z, h}^{\text {spot }}-\gamma_{z, h}^{\prime}-\beta_{z, h}^{\prime} P_{z, h}$

where $\gamma_{z, h}^{\prime}$ is the intercept and $\beta_{z, h}^{\prime}$ is the slope of the fringe supply in zone $z$ in hour $h$. After having estimated the supply functions of the fringe, from the first order conditions of Enel it is possible to compute $\alpha_{z, h}^{\prime}$ :

$\alpha_{z, h}^{\prime}=\frac{Q_{z, h}^{\text {spot }}}{\gamma_{z, h}^{\prime}+Q_{z, h}^{\text {Edison }}+2 Q_{z, h}^{\text {Enel }}-C^{\prime}\left(Q_{z, h}^{\text {Enel }}\right) \frac{\partial Q_{z, h}^{r}}{\partial P_{z, h}}}$

where $\frac{\partial Q_{2, h}^{r}}{\partial P_{z, h}}=-\beta_{z, h}^{\prime}$ is the slope of the residual demand function. The objective function of the small oligopolist Edison is:

$\max _{Q_{n, h}, Q_{s, h}} \sum_{z=n, s}\left(P_{z, h} Q_{z, h}^{\text {Edison }}-C\left(Q_{z, h}^{\text {Edison }}\right)\right)$. 
Given the inverse residual demand function:

$P_{z, h}=\frac{Q_{z, h}^{\text {spot }}-Q_{z, h}^{\text {Enel }}-Q_{z, h}^{\text {Edison }}-\gamma_{z, h}^{\prime}}{\beta_{z, h}^{\prime}}$

the best response function for Edison turns out to be:

$Q_{z, h}^{\text {Edison }}=\frac{Q_{z, h}^{\text {spot }}-Q_{z, h}^{\text {Enel }}-\gamma_{z, h}^{\prime}-C^{\prime}\left(Q_{z, h}^{E d i s o n}\right) \beta_{z, h}^{\prime}}{2}$

In the integrated market, the fringe supply and the residual demand result from the summation of the two zonal fringes and residual demands, respectively. Assuming that $\alpha$, in the integrated market is the weighted average of $\alpha_{n, h}^{\prime}$ and $\alpha_{s, h}^{\prime}$, Enel's and Edison's objective functions are given by

$\max _{Q_{h}^{\text {Enel }}} \alpha_{h}\left[P_{h} Q_{h}^{\text {Enel }}-C\left(Q_{h}^{\text {Enel }}\right)\right]-\left(1-\alpha_{h}\right) P_{h} Q_{h}^{\text {spot }}$

$\max _{Q_{h}^{\text {Edison }}} P_{h} Q_{h}^{\text {Edison }}-C\left(Q_{h}^{\text {Edison }}\right)$

where $P_{h}$ is $P_{h}=\frac{Q_{h}^{\text {spot }}-Q_{h}^{\text {Enel }}-Q_{h}^{\text {Edison }}-\gamma_{\text {north }}^{\prime}-\gamma_{\text {south }}^{\prime}}{\beta_{n}^{\prime}+\beta_{s}^{\prime}}$ and $Q_{h}^{\text {spot }}=Q_{n, h}^{\text {spot }}+Q_{s, h}^{\text {spot }}$, $Q_{h}^{\text {Enel }}=Q_{n, h}^{\text {Enel }}+Q_{s, h}^{\text {Enel }}, Q_{h}^{\text {Edison }}=Q_{n, h}^{\text {Edison }}+Q_{s, h}^{\text {Edison }}$.

From the first order conditions we obtain the best response functions and the corresponding optimal quantities and equilibrium prices:

$P_{h}=\frac{\left(1-\alpha_{h}\right) Q_{h}^{\text {spot }}+\alpha_{h}\left(\left[C^{\prime}\left(Q_{h}^{\text {Enel }}\right)+C^{\prime}\left(Q_{h}^{\text {Edison }}\right)\right] \frac{\partial Q_{h}^{r}}{\partial P_{h}}-\left(Q_{h}^{\text {Enel }}+Q_{h}^{\text {Edison }}\right)\right)}{2 \alpha_{h} \frac{\partial Q_{h}^{r}}{\partial P_{h}}}$

$Q_{h}^{\text {Enel }}=\frac{\left(2-\alpha_{h}\right) Q_{h}^{\text {spot }}-\alpha_{h}\left(\gamma_{n}^{\prime}+\gamma_{s}^{\prime}\right)+\alpha_{h} \frac{\partial Q_{h}^{r}}{\partial P_{h}}\left[2 C^{\prime}\left(Q_{h}^{\text {Enel }}\right)-C^{\prime}\left(Q_{h}^{E d i s o n}\right)\right]}{3 \alpha_{h}}$

$Q_{h}^{E d i s o n}=\frac{\left(2 \alpha_{h}-1\right) Q_{h}^{\text {spot }}-\alpha_{h}\left(\gamma_{n}^{\prime}+\gamma_{s}^{\prime}\right)+\alpha_{h} \frac{\partial Q_{h}^{r}}{\partial P_{h}}\left[2 C^{\prime}\left(Q_{h}^{\text {Edison }}\right)-C^{\prime}\left(Q_{h}^{\text {Enel }}\right)\right]}{3 \alpha_{h}}$ where $\gamma_{n}^{\prime}$ and $\gamma_{s}^{\prime}$ are the intercepts of the fringe supplies and $\frac{\partial Q_{h}^{r}}{\partial P_{h}}$ is the slope of the residual demand in the integrated market (that is $\left.\frac{\partial Q_{h}^{r}}{\partial P_{h}}=-\left(\beta_{n}^{\prime}+\beta_{s}^{\prime}\right)\right)$.

\section{References}

Baldick, R., Hogan, W., 2006. Stability of supply function equilibria: implications for daily versus hourly bids in a Poolco market. Journal of Regulatory Economics 30 (2), 119-139.

Boffa, F., Pingali, V., 2006. Interconnection, congestion and welfare in the Italian electricity market: HERMES Working Paper Series, vol. 6.

Bolle, F., 1992. Supply function equilibria and the danger of tacit collusion. Energy Economics 14 (2), 94-102.

Borenstein, S., Bushnell, J., 1999. An empirical analysis of the potential for market power in California's electricity industry. Journal of Industrial Economics, XLVII 3, 285-323.

Borenstein, S., Bushnell, J., Kahn, E., Stoft, S., 1995. Market power in California electricity market. Utilities Policy 5 (3-4), 219-236.

Borenstein, S., Bushnell, J., Stoft, S., 2000. The competitive effects of transmission capacity in a deregulated electricity industry. Rand Journal of Economics 31 (Summer), 294-325.

Borenstein, S., Bushnell, J.B., Wolak, F.A., 2002. Measuring market inefficiencies in California's restructured wholesale electricity market. American Economic Review 92, 1376-1405.

Bushnell, J., Mansur, E.T., Saravia, C., 2008. Vertical arrangements, market structure and competition: an analysis of restructured US electricity markets. American Economic Review 98 (1), 237-266.

Green, R., Newbery, D., 1992. Competition in the British electricity spot market. Journal of Political Economy 100 (5), 929-953.

Harvey, S, Hogan, W., Pope, S., 1996. Transmission capacity reservations implemented through a spot market with transmission congestion contracts. Electricity Journal 9 (9) 42-55.

Hortaçsu, A., Puller, S., 2008. Understanding strategic bidding in multi-unit auctions: a case study of the Texas electricity spot market. RAND Journal of Economics 39 (1), 86-114.

Johnsen, A., Verma, S., Wolfram, C., 2004. Zonal pricing and demand-side responsiveness in the Norwegian electricity market. Working Paper 063, POWER.

Joskow, P., Tirole, J., 2005. Merchant transmission investment. Journal of Industrial Economics 53 (2), 233-264.

Kamat, R., Oren, S.S., 2004. Two-settlement systems for electricity markets under network uncertainty and market power. Journal of Regulatory Economics 25 (1), 5-37.

Puller, S., 2007. Pricing and firm conduct in California's deregulated electricity market Review of Economics and Statistics 89 (1), 75-87.

Sweeting, A., 2007. Market power in the England and Wales wholesale electricity market 1995-2000. Economic Journal 117, 654-685.

Wolak, F., 2000. An empirical analysis of the impact of hedge contracts on bidding behavior in a competitive electricity market. International Economic Review 14 (2), 1-39.

Wolak, F., 2003. Identification and estimation of cost functions using observed bid data: an application to electricity markets. In: Dewatripont, M., Hansen, L.P., Turnovsky, S.J. (Eds.), Advances in Economics and Econometrics: Theory and Applications, Vol. II.

Wolfram, C., 1999. Measuring duopoly power in the British electricity spot market. American Economic Review 89 (4), 805-826. 